\title{
DIE GEBRUIK VAN DIE SWEEDSE SKAAL BY DIE KEURING VAN VERPLEEGKUNDE STUDENTE AAN DIE RANDSE AFRIKAANSE UNIVERSITEIT
}
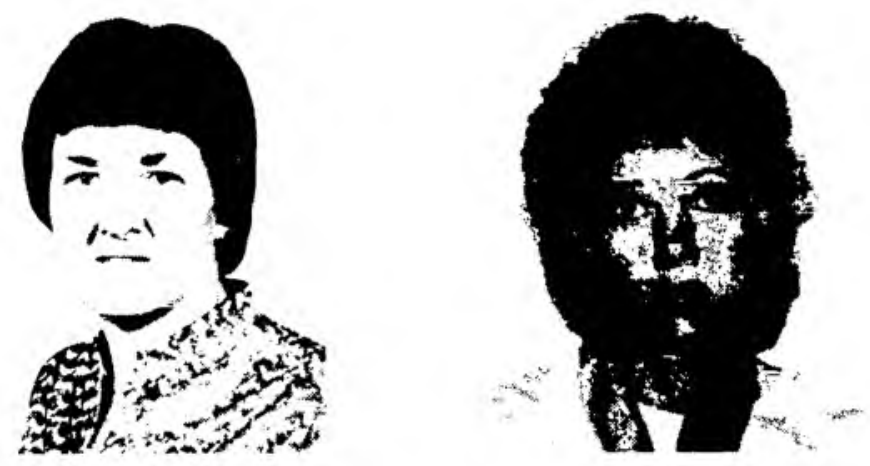

Annali Basson, Annatjie Botes

\section{Abstract}

Students applying to follow the B.Cur. degree at the Rand Afrikaans University are subjected to a selection process. In spite of the selection process the drop-out rate is high. An attempt is being made to evaluate the present academic selection process.

The amended Smeltzer method is used as a point of departure to correlate with the model proposed by the University administration. The academic predictions are implemented on the Swedish formula and a cut-off point is obtained according to a sliding scale proposed for academic selection.
With the abovementioned two methods it appears that the selected population has the most successful academic results if the cut-off point of the amended Smeltzer method and the Swedish formula is 60 and 15 respectively.

\section{Uittreksel}

Studente wat beplan om die B.Curgraad te doen aan die R.A.U. word onderwerp aan in keuringsproses. Ten spyte van die keuring is die uitvalsyfer hoog. ' $n$ Poging is aangewend om die huidig ' akademiese keuringsproses te evalueer.

Om korrelerend te wees met die model wat deur die universiteitsbestuur voorgestel is, is die gewysigde Smeltzermetode as vertrekpunt gebruik. Die akademiese voorspellers is op die Sweedse formule geimplementeer en 'n afsnypunt is volgens glyskaal verkry wat voorgestel word vir akademiese keuring.

Met genoemde twee metodes blyk dit dat die geselekteerde populasie die suksesvolste akademiese uitslae het as die afsnypunt of die gewysigde Smeltzer-metode en die Sweedse formule, 60 en 15 respektiewelik is.

\section{INLEIDING}

Ten spyte van talle ondersteunende en student-adviesdienste wat aan universiteite ingestel is, bly die druipsyfer aan universiteite, veral onder eerstejaars besonder hoog (Stoker et al., 1985:1).

Verskeie navorsers wat naas ander sake ook op die geldigheid van die matrikulasieeksamenpunte as voorspeller van sukses op universiteitsvlak ingegaan het, het gevind dat sukses op skool in 'n redelike mate verband hou met prestasie op universiteit, veral in die eerste jaar (Conradie, 1974; Wessels, 1976; Gouden, 1977).

Die Raad van Geesteswetenskaplike Navorsing het in 1985 'n universele studie in die Republiek van Suid-Afrika gedoen oor die differensiele toelatingsvereistes tot tersiêre onderriginstansies. Die studie het egter nie verpleegkunde studente aan universiteite ingesluit nie. Studente aan verplegingskolleges was wel by die ondersoek betrek. Die volgende veranderlikes is in orde van prioriteit as voorspellers van akademiese sukses in die geval uitgewys, naamlik:

- skoolgroottotaal; eerste taal; vakgroep E (aardrykskunde, bybelkunde, ekonomie en geskiedenis); wiskunde, biologie en natuur- en skeikunde

(Stoker, Engelbrecht, Crowther, du

Toit en Herbst, 1985:121).

Smeltzer (1965:19) is van mening dat ' $n$ student wat verpleegkunde oorweeg 'n besondere vermoë in taalkundige en wetenskaplike vakke moet hè, aangesien die vakke volgens genoemde skrywer verpleegkunde ten grondslag lê.

Volgens Basson (1981;3/88) is die uitvalsyfer, veral onder eerstejaars in die verpleegkunde besonder hoog. Die Randse
Afrikaanse Universiteit gebruik sedert 1975 die gewysigde Smeltzer-metode (1965:162) (sien figuur 5.1) vir akademiese keuring by verpleegkunde studente. Die navorsing deur Basson in 1981 gedoen het gevind dat keuring volgens die metode 'n goeie voorspeller vir akademiese sukses is

Volgens Furneaux (1961:107) is die probleem van keuring van universiteitstudente om 'n afsnypunt op 'n spesifieke skaal te bepaal wat akademiese sukses kan voorspel.

Daar bestaan ' $n$ behoefte om die matrikulasiesimbole op 'n eenvoudige, dog effektiewe wyse te vertolk met die oog op keuring van voornemende studente aan 'n universiteit. Die bestuur van die Randse Afrikaanse Universiteit het voorgestel dat die Sweedse-metode (sien figuur 4.2) vir die doel aangepas word. 


\section{PROBLEEMSTELLING}

Om korrelerend te wees met die model wat deur die universiteitsbestuur en Jacobs (1987:36) voorgestel is, is dit nodig om die gewysigde Smeltzer-metode van keuring soos sedert 1975 deur die departement verpleegkunde van die Randse Afrikaanse Universiteit as vertrekpunt te gebruik. Die akademiese voorspellers soos blyk uit die literatuurstudie op die aanbevole Sweedse formule te implementeer en 'n glyskaal en afsnypunt vir akademiese keuring van die B.Cur studente aan die Randse Afrikaanse Universiteit te beskryf en voor te stel.

\section{DIE DOEL MET DIE ONDERSOEK}

Die doel met die ondersoek is om vir die doeleindes van akademiese keuring van verpleegkunde studente aan die Randse Afrikaanse Universiteit na die Sweedsemetode oor te skakel deur:

- die gewysigde Smeltzer as vertrekpunt te gebruik;

- aanpassings met betrekking tot akademiese voorspellers te maak soos blyk uit die literatuurstudie;

- 'n glyskaal en afsnypunt op die Sweedse skaal beskryf en voor te stel.

\section{LITERATUURSTUDIE}

\section{Oriëntasie}

Die toelatingsvereistes tot tersière studie is 'n aangeleentheid wat deurentyd in die brandpunt van die belangstelling van beleidmakers en beplanners lê.

In die navorsing is gekyk na die moontlikheid om op grond van prestasies wat in sekere skoolvakkombinasies behaal is, daar te stel.

\section{Sukses aan Universiteite}

Die probleem van druiping aan universiteite is nie nuut nie. In Julie 1938 het $d r$. Malherbe al in 'n rede "Whiter Matric?" daarop gewys dat dit uit 'n totaal van nagenoeg 8000 studente tussen 1930 en 1935 aan Suid-Afrikaanse Universiteite ingeskryf het, daar 3185 (d.w.s. bykans 40\%) was wat in hulle eerste studiejaar aan die Universiteit gedruip het (Le Roux, 1976:1). In 1957 het dr. Gouws sy proefskrif oor die akademiese vordering en aanpassing van eerstejaar studente aan die Universiteit van Pretoria gedurende die tydperk tussen 1952 en 1955 voltooi (Gouws, 1961).

'n Hele reeks verwante studies is ook deur ander navorsers aan verskillende universiteite onderneem. Voorbeelde hiervan is Sonnekus (1959), van Biljon (1961), Möller (1965), van Tonder (1969), Botha (1971), Smit (1971), Steyn (1971), Herholdt (1972), Conradie (1974), Wessels (1976) en Gouden (1977), wat almal naas ander sake ook op die geldigheid van die matrikulasie-eksamenpunte as voorspeller van sukses op universiteitsvlak ingegaan het en wat almal bevind het dat sukses op skool in 'n redelike mate verband hou met prestasies op universiteit, veral in die eerste studiejaar.
Sukses vir verpleegkundiges

Aan universiteit is wel enkele ondersoeke onderneem oor die sukses van studentverpleegkundiges aldaar. In die verband kan verwys word na die ondersoek van van Huyssteen en Fölscher (1978), Basson (1981) en Mearns (1980).

Bogenoemde navorsing is by die RAU gedoen behalwe vir Mearns (1980). Vir die akademiese keuring is gebruik gemaak van die rekenkundige gemiddeld van die simbole behaal in matriekvakke.

$\mathrm{K}$ redietpunte is bereken volgens die gewysigde Smeltzer-metode (1965:31). Vir vorige tersiêre bywoning is kredietpunte gegee. Daar is ook gedifferensiëer tussen vakke op hoërgraad en laergraad geslaag (Figuur 1).

By die RAU word tans die Sweedseformule vir keuring van studente voorgestel en ook gebruik deur sommige departemente. Waar die vlakke van keuring tussen universiteite om geldige redes nie identies kan wees nie, is dit ook nie wenslik om dieselfde maatstaf te gebruik nie. Die Departement Verpleegkunde oorweeg egter om die
Sweedse skaal moontlike te implementeer en sodoende in lyn met die res van die RAU te kom vir konsekwentheid. Die berekeninge by laasgenoemde formule is ook eenvoudiger van aard.

Dit blyk egter uit vorige navorsing soos voorheen genoem, dat sekere vakkombinasies vir voornemende verpleegkunde kandidate ongetwyfeld goeie voorspellers vir akademiese sukses is in die eerste jaar van studie aan 'n universiteit.

Smeltzer (1965:21) is van mening dat biologie en natuur- en skeikunde 'n goeie onderbou is vir 'n kursus in die verpleegkunde. Wiskunde word beskou as 'n vak wat verbandlegging vergemaklik en 'n derde taal is 'n goeie voorspeller.

Basson (1981:30) toon aan dat studente met ' $n$ vakkombinasies van wiskunde, natuur- en skeikunde die hoogste slaagpersentasie het (slegs wiskunde, wetenskap en biologie as vakkombinasies is getoets). Die groep studente met wiskunde, wetenskap en biologie as vakkombinasie toon die tweede hoogste slaagpersentasie, terwyl studente met wiskunde en biologie as vakkombinasie die

Figuur 4.1.

Keuringsglyskaal: Smeltzer

- Skoolgroottotaal

Die rekenkundige gemiddeld word bereken van die simbole behaal in matriek vakke.

- Vakke op Hoërgraad geslaag

Twee (2) punte vir elke vak, meer as die vereiste vier (4) vakke op H.S. geslagg.

- Akademiese voorspellers

Krediet punte word as volg bereken:

Wiskunde, Natuur- en Skeikunde, Biologie, 'n derde taal.

$\begin{array}{lcc}\text { GLYSKAAL } & \text { H.G. (HOERGRAAD) } & \text { S.G. (STANDAARDGRAAD) } \\ 90 \%-100 \% & 12 & 6 \\ 80 \%-89 \% & 10 & 5 \\ 70 \%-78 \% & 8 & 4 \\ 60 \%-69 \% & 6 & 3 \\ 50 \%-59 \% & 4 & 2 \\ 40 \%-49 \% & 2 & 0\end{array}$

Figuur $4.2 \mathrm{~A}$

Keuringsglyskaal: Sweedse Skaal A

- Skoolgroottotaal en akademiese voorspellers

Volgens die onderstaande saak word punte vir ses standerd tien vakke toegeken volgens simbole behaal. Die voorspellervakke se telling word verdubbel.

SIMBOOL

A
B
C
D
HOERGRAAD

8
6
4
2

Figuur 4.2 B

Keuringsglyskaal: Sweedse Skaal B

- Skoolgroottotaal en akademiese voorspellers Volgens die onderstaande skaal word punte vir ses standerd tien vakke toegeken volgens simbole behaal. Die voorspellersvakke se telling word verdubbel. SIMBOOL

HOERGRAAD STANDAARDGRAAD

$\begin{array}{lll}\text { A } & 5 & \\ \text { B } & 4 & 4 \\ \text { C } & 3 & 3 \\ \text { D } & 2 & 2 \\ \text { E } & 1 & 1\end{array}$


Figuur 4.3

Skoolvakgroep van die Gemeenskaplike Matrikulasieraad

GROEP A: Afrikaans en Engels

GROEP B: Wiskunde

GROEP C: Biologie en Natuur- en Skeikunde

GROEP D: Duits, Frans, Latyn, verskillende swart tale, ens.

GROEP E: Aardrykskunde, Bybelkunde, Ekonomie en Geskiedenis

GROEP F: Bedryfsekonomie, Huishoudkunde, Kuns, Musiek, Rekeningkunde,

Tik, ens.

laagste slaagpersentasie in hul eerste jaar toon.

By kandidate wat wel Groep E vakke het mag dit moontlik tog 'n sterk aanbeveling wees aangesien hierdie keuse, leervakke is en dus leerretensie mag weergee. Om die Groep E vakke egter as voorspeller vir die B.Cur graad te gebruik mag onwys wees, omdat baie min kandidate hierdie groep in matriek insluit by hul pakket en dit dus diskriminerend mag inwerk op die totale keuringsaansoeke.

\section{RGN ondersoek na differensiële}

toelatingsvereistes

Tydens 'n ondersoek wat gedoen is deur die RGN (1985:53), na onder andere moontlike skoolvakgroepe vir akademiese sukses in die eerste studiejaar op

Universiteit, kom die volgende duidelik na vore.

- B.Sc. (Wiskunde)-studierigting: Skoolgroottotaal blyk 'n hoogs betekenisvolle verklaarder te wees.

Daar is aanduidings dat natuur-en skeikunde ook 'n bydrae lewer. Sonder skoolgroottotaal as 'n verklaarde blyk wiskunde, natuur- en skeikunde, biologie en vakgroep $E$ die sterkste voorspellers te wees.

- B.Med-studierigting: Skoolgroottotaal kom hier nie as 'n statistiese betekenisvolle verklaarder na vore nie, maar wel die prestasies in wiskunde, natuur- en skeikunde, biologie, 'n derde taal en vakgroep $E$.

Die studie deur die RGN gedoen in 1985 sluit nie verpleegkunde studente aan universiteite in nie. As egter gekyk word na bogenoemde twee studierigtings blyk dit dat wiskunde, natuur-en skeikunde by albei sterk akademiese voorspellers is. Laasgenoemde studierigting mag moontlik ooreenstem met die kursus komponente van die Baccalaureus in Verpleegkunde aangesien beide gesondheidswetenskappe is.

\section{VOORONDERSTELLINGS EN DIE METODE VAN DIE ONDERSOEK} Domein vooronderstellings

Die navorsers handhaaf die domeinvooronderstelling dat

- daar 'n groot verskil is tussen die kognitiewe vlak van die voorspellingsvakke op hoër- en standaardgraad.

- aangesien die proefpersone nog nie die graad voltooi het nie, sukses tot dusver geneem as 'n voltallige aantal kursusse geslaag tot op hede volgens die voorgeskrewe kursusregulasie. Proefpersone kan dus kursusse gedruip en dit ingehaal het.

\section{Die metode van ondersoek}

Die metode van ondersoek uit twee dele, naamlik 'n literatuurstudie en 'n empiriese ondersoek.

Die studie van die relevante literatuur $\mathrm{Om}$ as teoretiese raamwerk en grondslag vir die empiriese ondersoek te dien, is 'n studie van die relevante literatuur gedoen

\section{Die empiriese ondersoek}

Die empiriese gedeelte van die ondersoek bestaan uit ' $n$ gevallestudie op B.Curstudente in 1986-1987 met die oog op 'n kontektuele beskrywing van:

(a) die akademiese voorspellingswaarde van die huidige gewysigde Smeltzermetode soos in gebruik by die Departement Verpleegkunde, RAU sedert 1975 met skoolgroottotaal, wiskunde, natuur- en skeikunde, biologie en 'n derde taal as voorspellers van akademiese sukses.

Wysiging in die akademiese voorspellers soos blyk uit die literatuurstudie is in die Sweedse formule (A) en (B) (figuur 4.2) geoperasionaliseer om

(b) die akademiese voorspellingswaarde van die Sweedse formule (figuur 4.2A) met skoolgroottotaal, wiskunde, natuur- en skeikunde en biologie as voorspellers van akademiese sukses.

(c) die akademiese voorspellingswaarde van die Sweedse formule (A) met skoolgroottotaal, eerste taal, wiskunde, natuur- en skeikunde en biologie as voorspellers van akademiese sukses.

(d) die akademiese voorspellingswaarde van die Sweedse formule (A) met skoolgroottotaal, eerste taal, wiskunde as voorspellers van akademiese sukses.

(e) die akademiese voorspellingswaarde van die Sweedse formule (B) (figuur 4.2B) met skoolgroottotaal, eerste taal, wiskunde, natuur- en skeikunde en biologie as voorspellers van akademiese sukses.

(f) van die afsnypunt vir keuring van B.Cur studente aan die RAU op die Sweedse skaal met die mees geskikte voorspellingswaarde.

\section{Populasie en steekproef}

Uit die populasie studente wat in 1986 en 1987 die graad B.Cur (wat oor 4 jaar strek) aan die RAU begin het, is van 'n doelbewuste seleksie gebruik gemaak deurdat studente wat om nie-akademiese redes onsuksesvol was uit die steekproef te sluit. Alle ander studente van die jare (suksesvol en nie-suksesvol) is by die steekproef ingesluit.

\section{DIE BEVINDINGS VAN DIE \\ NAVORSING}

Met die gevallestudie op B.Cur studente van 1986-1987 is die volgende resultaat gekry.

Met die kontekstuele beskrywing van die akademiese voorspellingswaarde van die huidige gewysigde Smeltzer soos by die RAU in gebruik met skoolgroottotaal, wiskunde, natuur- en skeikunde, biologie en 'n derde taal as voorspellers van akademiese sukses, is die volgende gevind.

$\mathrm{f}=$ frekwensie

$\mathrm{kf}=$ kumulatiewe frekwensie

$\%=$ persentasie

Op 'n afsnypunt van 60 is $100 \%$ van die

TABEL 6.1 BEVINDINGS VAN DIE AKADEMIESE VOORSPELL INGSWAARDE MET BEHULP VAN DIE GEWYSIGDE SMELTZER MET SKOOLGROOTTOTAAL, WISKUNDE, NATUUR - EN SKEIKUNDE, BIOLOGIE EN 'N DERDE TAAL AS VOORSPELLER

\begin{tabular}{|c|c|c|c|c|c|c|c|c|c|c|c|c|}
\hline \multirow{3}{*}{ SMELTZER SKAAL } & \multicolumn{6}{|c|}{1986} & \multicolumn{6}{|c|}{1987} \\
\hline & \multicolumn{3}{|c|}{ SUKSES } & \multicolumn{3}{|c|}{ NIE SUKSES } & \multicolumn{3}{|c|}{ SUKSES } & \multicolumn{3}{|c|}{ NIE SUKSES } \\
\hline & $f$ & $k f$ & $\%$ & $f$ & $k f$ & $\%$ & $\mathrm{f}$ & $k f$ & $\%$ & $f$ & $\mathrm{kf}$ & $\%$ \\
\hline $60-64$ & 0 & 9 & 100 & 4 & 8 & 100 & 1 & 23 & 100 & 4 & 16 & 100 \\
\hline $65-69$ & 1 & 9 & 100 & 4 & 4 & 50 & 0 & 22 & 97 & 5 & 12 & 75 \\
\hline $70-74$ & 3 & 8 & 89 & 0 & 0 & 0 & 3 & 22 & 97 & 2 & 7 & 44 \\
\hline $75-79$ & 1 & 5 & 56 & 0 & 0 & 0 & 4 & 19 & 83 & 2 & 5 & 37 \\
\hline $80-84$ & 1 & 4 & 44 & 0 & 0 & 0 & 3 & 15 & 65 & 1 & 3 & 19 \\
\hline $85-89$ & 1 & 3 & 33 & 0 & 0 & 0 & 6 & 12 & 53 & 2 & 2 & 13 \\
\hline $90-94$ & 0 & 2 & 22 & 0 & 0 & 0 & 3 & 6 & 26 & 0 & 0 & 0 \\
\hline $95-99$ & 1 & 2 & 22 & 0 & 0 & 0 & 2 & 3 & 13 & 0 & 0 & 0 \\
\hline $100-104$ & 0 & 1 & 11 & 0 & 0 & 0 & 0 & 1 & 4 & 0 & 0 & 0 \\
\hline $105-109$ & 1 & 1 & 11 & 0 & 0 & 0 & 0 & 1 & 4 & 0 & 0 & 0 \\
\hline $110-114$ & 0 & 0 & 0 & 0 & 0 & 0 & 1 & 1 & 4 & 0 & 0 & 0 \\
\hline TOTAAL & 9 & & & 8 & & & 23 & & & 16 & & \\
\hline
\end{tabular}


suksesvolle studente van 1986 en 1987 ingesluit en ook $100 \%$ van die studente van 1986 en 1987 wat nie suksesvol was nie. Op 'n afsnypunt van 65 sou $100 \%$ van die 1986 se suksesvolle studente ingesluit gewees het en $50 \%(n=4)$ van die jaar se niesuksesvolle studente sou uitgesluit gewees het. Van die 1987 studente sou $3 \%(n=1)$ van die suksesvolle studente op 'n afsnypunt van 65 vir die kursus uitgeskakel gewees het maar ook $25 \%(n=4)$ van die nie-suksesvolle studente.
Op die Sweedse formule A (vergelyk literatuurstudie) met skoolgroottotaal, wiskunde, natuur- en skeikunde en biologie as voorspellers van akademiese sukses is die volgende resultaat verkry.

Wanneer die Sweedse formule A me skoolgroottotaal, wiskunde, natuur-en skeikunde en biologie as voorspellers toegepas word, sal op 'n afsnypunt van 15, $100 \%$ van die suksesvolle studente van 1986 en 1987 ingesluit wees het. Die afsnypunt sou $50 \%(n=4)$ van die nie-

TABEL 6.2 BEVINDINGS VAN DIE AKADEMIESE VOORSPELLINGSWAARDE MET BETREKKING TOT DIE SWEEDSE FORMULE A MET SKOOLGROOTTOTAAL, WISKUNDE, NATUUREN SKEIKUNDE EN BIOLOGIE AS VOORSPELLERS

\begin{tabular}{|c|c|c|c|c|c|c|c|c|c|c|c|c|c|}
\hline \multirow{3}{*}{\multicolumn{2}{|c|}{ SWEEDSE SKAAL }} & \multicolumn{6}{|c|}{1986} & \multicolumn{6}{|c|}{1987} \\
\hline & & \multicolumn{3}{|c|}{ SUKSES } & \multicolumn{3}{|c|}{ NIE SUKSES } & \multicolumn{3}{|c|}{ S!IKSES } & \multicolumn{3}{|c|}{ HIE SUKSES } \\
\hline & & $\mathrm{f}$ & $k f$ & $q$ & $f$ & $\mathrm{kf}$ & $\%$ & $f$ & $\mathrm{kf}$ & $\%$ & $f$ & $\mathrm{kf}$ & $\%$ \\
\hline 0. & -5 & 0 & 9 & 100 & 1 & 8 & 100 & 0 & 23 & 100 & 0 & 16 & 100 \\
\hline $6-$ & -9 & 0 & 9 & 100 & 1 & 7 & 88 & 0 & 23 & 100 & 2 & 16 & 100 \\
\hline $10-$ & -14 & 0 & 9 & 100 & 2 & 6 & 75 & 0 & 23 & 100 & 5 & 14 & 88 \\
\hline 15 & $-\quad 19$ & 2 & 9 & 100 & 4 & 4 & 50 & 2 & 23 & 100 & 5 & 9 & 56 \\
\hline 20 & -24 & 3 & 7 & 78 & 0 & 0 & 0 & 4 & 21 & 91 & 2 & 4 & 25 \\
\hline 25 & $-\quad 29$ & $0 !$ & 4 & 44 & 0 & 0 & 0 & 4 & 17 & 74 & 2 & 2 & 13 \\
\hline 30 & - 34 & 1 & 4 & 44 & 0 & 0 & 0 & 5 & 13 & 57 & 0 & 0 & 0 \\
\hline $35-$ & $-\quad 37$ & 1 & 3 & 33 & 0 & 0 & 0 & 3 & 8 & 35 & 0 & 0 & 0 \\
\hline $40-$ & -44 & 0 & 2 & 22 & 0 & 0 & 0 & 1 & 5 & 22 & 0 & 0 & 0 \\
\hline 45 & -49 & 0 & 2 & 22 & 0 & 0 & 0 & 1 & 4 & 17 & 0 & 0 & 0 \\
\hline $50-$ & -54 & 1 & 2 & 22 & 0 & 0 & 0 & 2 & 3 & 13 & 0 & 0 & 0 \\
\hline $55-$ & $-\quad 59$ & 1 & 1 & 11 & 0 & 0 & 0 & 0 & 1 & 4 & 0 & 0 & 0 \\
\hline $60-$ & -64 & 0 & 0 & 0 & 0 & 0 & 0 & 1 & 1 & 4 & 0 & 0 & 0 \\
\hline $65-$ & -69 & 0 & 0 & 0 & 0 & 0 & 0 & 0 & 0 & 0 & 0 & 0 & 0 \\
\hline TOTA & AAL & 9 & & & 8 & & & 23 & & & 16 & & \\
\hline
\end{tabular}

TABEL 6.3 DIE BEVINDINGS VAN DIE AKADEMIESE VOORSPELLINGSWAARDE MET BEHULP VAN SWEEDSE FORMULE A MET SKOOLGROOTTOTAAL, EERSTE TAAL, WISKUNDE NATUUR- EN SKEIKUNDE EN BIOLOGIE AS VOORSPELLERS

\begin{tabular}{|c|c|c|c|c|c|c|c|c|c|c|c|c|}
\hline \multirow[t]{3}{*}{ SWEEDSE SKAAL } & \multicolumn{6}{|c|}{1986} & \multicolumn{6}{|c|}{1987} \\
\hline & \multicolumn{3}{|c|}{ SUKSES } & \multicolumn{3}{|c|}{ NIE SUKSES } & \multicolumn{3}{|c|}{ SIJKSES } & \multicolumn{3}{|c|}{ NIE SUKSES } \\
\hline & $f$ & $\mathrm{kf}$ & $\%$ & $f$ & $\mathrm{kf}$ & $\%$ & $f$ & $\mathrm{kf}$ & $\dot{z}$ & $f$ & $\mathrm{kf}$ & $\%$ \\
\hline $0-4$ & 0 & 9 & 100 & 0 & 8 & 100 & 0 & 23 & 100 & 0 & 16 & 100 \\
\hline $5-9$ & 0 & 9 & 100 & 1 & 8 & 100 & 0 & 23 & 100 & 1 & 16 & 100 \\
\hline $10-14$ & 0 & 9 & 100 & 1 & 7 & 86 & 0 & 23 & 100 & 5 & 15 & 94 \\
\hline $15-19$ & 1 & 9 & 100 & 4 & 6 & 75 & 2 & 23 & 75 & 4 & 10 & 63 \\
\hline $20-24$ & 2 & 8 & 89 & 2 & 2 & 25 & 1 & 21 & 91 & 2 & 6 & 38 \\
\hline $25-29$ & 2 & 6 & 67 & 0 & 0 & 0 & 2 & 20 & 87 & 1 & 4 & 25 \\
\hline $30-34$ & 1 & 4 & 44 & 0 & 0 & 0 & 3 & 18 & 78 & 3 & 3 & 19 \\
\hline $35-39$ & 1 & 3 & 33 & 0 & 0 & 0 & 5 & 15 & 65 & 0 & 0 & 0 \\
\hline $40-44$ & 1 & 2 & 22 & 0 & 0 & 0 & 4 & 9 & 39 & 0 & 0 & 0 \\
\hline $45-49$ & 0 & 1 & 11 & 0 & 0 & 0 & 2 & 5 & 22 & 0 & 0 & 0 \\
\hline $50-54$ & 0 & 1 & 11 & 0 & 0 & 0 & 0 & 3 & 13 & 0 & 0 & 0 \\
\hline $55-59$ & 1 & 1 & 11 & 0 & 0 & 0 & 1 & 3 & 13 & 0 & 0 & 0 \\
\hline $60-64$ & 0 & 0 & 11 & 0 & 0 & 0 & 2 & 2 & 9 & 0 & 0 & 0 \\
\hline $65-69$ & 0 & 0 & 11 & 0 & 0 & 0 & 0 & 0 & 0 & 0 & 0 & 0 \\
\hline TOTAAL & 9 & & & 8 & & & 23 & & & 16 & & \\
\hline
\end{tabular}

suksesvolle studente van 1986 en $44 \%$ ( $n=$ 7) van die nie-suksesvolle studente van 1987 uitgeskakel het.

Op die Sweedse formule A (vergelyk literatuurstudie) met skoolgroottotaal, eerste taal, Afrikaans, wiskunde, natuuren skeikunde en biologie as voorspellers van akademiese sukses is die volgende resultaat verkry.

Wanneer die Sweedse formule $A$ met skoolgroottotaal, eerste taal, wiskunde, natuur-en skeikunde en biologie as voorspellers gebruik word, word op 'n afsnypunt van $15100 \%$ van die suksesvolle studente van 1986 ingesluit. Van die 1987 studente word $25 \%(\mathrm{n}=2)$ van die suksesvolle kandidate egter uitgesluit. Van die studente van 1986 word op 'n

afsnypunt van $15,25 \%(\mathrm{n}=2)$ van die niesuksesvolle kandidate en van die 1987 studente $37 \%(n=6)$ uitgesluit.

Op die Sweedse formule A (vergelyk literatuurstudie) met skoolgroottotaal, wiskunde en eerste taal as voorspellers vir akademiese sukses is die volgende resultaat gekry.

Met die Sweedse formule A moet skoolgroottotaal, wiskunde en eerste taal word op 'n afsnypunt van $10100 \%$ van die suksesvolle kandidate van 1986 en 1987 ingesluit. $25 \%(\mathrm{n}=2)$ van die nie-

suksesvolle kandidate van 1986 en $6 \%(n=$ 1) van 1987 word uitgesluit.

Indien die afsnypunt na 15 verhoog word, word een suksesvolle studente van 1986 en 1987 uitgeskakel asook 3, (37\%) en 4, (25\%) van die nie-suksesvolle kandidate van 1986 en 1987 onderskeidelik. Op die glyskaal tussen $25-29$ sou $4,(25 \%)$ van die nie-suksesvolle kandidate van 1987 geval het terwyl slegs $65 \%(n=15)$ van die suksesvolle kandidate ingesluit sou wees.

Op die Sweedse formule A (vergelyk literatuurstudie) met skoolgroottotaal, wiskunde en eerste taal as voorspellers vir akademiese sukses is die volgende resultaat gekry.

Met die Sweedse formule A met skoolgroottotaal wiskunde en eerste taal word op 'n afsnypunt van $10(100 \%)$ van die suksesvolle kandidate van 1986 en 1987 ingesluit. $25 \%(\mathrm{n}=2)$ van die niesuksesvolle kandidate van 1986 en $6 \%(\mathrm{n}=$ I) van 1987 word uitgesluit. Indien die afsnypunt na 15 verhoog word, word een suksesvolle studente van 1986 en 1987 uitgeskakel asook $3(37 \%)$ van $4(25 \%)$ van die nie-suksesvolle kandidate van 1986 en 1987 onderskeidelik. Op die glyskaal tussen $25-29$ sou 4 (25\%) van die niesuksesvolle kandidate van 1987 geval het, terwyl slegs $65 \%(n=15)$ van die suksesvolle kandidate ingesluit sou wees.

Op die Sweedse formule B (vergelyk literatuurstudie) met skoolgroottotaal, eerste taal, wiskunde, natuur- en skeikunde en biologie as voorspellers van akademiese sukses is die volgende resultaat verkry.

Wanneer die Sweedse formule B met skoolgroottotaal, eerste taal, wiskunde, natuur- en skeikunde en biologie as voorspellers gebruik word, word op 'n afsnypunt van $15(100 \%)$ van die 1986 en $96 \%$ van die suksesvolle kandidate van 1987 ingesluit. Dieselfde afsnypunt sou $12 \%(n=1)$ van die nie-suksesvolle 
TABEL 6.4 DIE BEVINDINGS VAN DIE AKADEMIESE VOORSPELLINGSWAARDE MET BEHULP VAN DIE SWEEDSE FORMULE A MET SKOOLGROOTTOTAAL, WISKUNDE EN EERSTE TAAL AS VOORSPELLERS

\begin{tabular}{|c|c|c|c|c|c|c|c|c|c|c|c|c|c|}
\hline \multirow{3}{*}{\multicolumn{2}{|c|}{ SWEEDSE FORMULE }} & \multicolumn{6}{|c|}{1986} & \multicolumn{6}{|c|}{1987} \\
\hline & & \multicolumn{3}{|c|}{ SUKSES } & \multicolumn{3}{|c|}{ NIE SUKSES } & \multicolumn{3}{|c|}{ SUKSES } & \multicolumn{3}{|c|}{ NIE SUKSES } \\
\hline & & $f$ & $k f$ & q & $f$ & $k f$ & $\%$ & $f$ & $k f$ & $\%$ & $f$ & $k f$ & $\mathscr{\phi}$ \\
\hline 0 & -4 & 0 & 9 & 100 & 0 & 8 & 100 & 0 & 23 & 100 & 0 & 16 & 100 \\
\hline 5 & -9 & 0 & 9 & 100 & 2 & 8 & 100 & 0 & 23 & 100 & 1 & 16 & 100 \\
\hline 10 & -14 & 1 & 9 & 100 & 1 & 6 & 75 & 1 & 23 & 100 & 3 & 15 & 94 \\
\hline 15 & -19 & 2 & 8 & 89 & 4 & 5 & 63 & 2 & 22 & 96 & 6 & 12 & 75 \\
\hline 20 & -24 & 1 & 6 & 67 & 1 & 1 & 13 & 5 & 20 & 87 & 1 & 6 & 38 \\
\hline 25 & -29 & 1 & 5 & 56 & 0 & 0 & 0 & 7 & 15 & 65 & 4 & 5 & 31 \\
\hline 30 & $-\quad 34$ & 0 & 4 & 44 & 0 & 0 & 0 & 2 & 8 & 35 & 1 & 1 & 16 \\
\hline 35 & - $\quad 39$ & 1 & 4 & 44 & 0 & 0 & 0 & 1 & 6 & 26 & 0 & 0 & 0 \\
\hline 40 & $-\quad 44$ & 1 & 3 & 33 & 0 & 0 & 0 & 3 & 5 & 22 & 0 & 0 & 0 \\
\hline 45 & -49 & 2 & 2 & $2 i$ & 0 & 0 & 0 & 1 & 2 & 9 & 0 & 0 & 0 \\
\hline 50 & -54 & 0 & 0 & 0 & 0 & 0 & 0 & 1 & 1 & 4 & 0 & 0 & 0 \\
\hline 55 & $-\quad 59$ & 0 & 0 & 0 & 0 & 0 & 0 & 0 & 0 & 0 & 0 & 0 & 0 \\
\hline 60 & -64 & 0 & 0 & 0 & 0 & 0 & 0 & 0 & 0 & 0 & 0 & 0 & 0 \\
\hline 65 & $-\quad 69$ & 0 & 0 & 0 & 0 & 0 & 0 & 0 & $\underline{0}$ & 0 & 0 & 0 & 0 \\
\hline & TOTAAL & 9 & & & 8 & & & 23 & & & 16 & & \\
\hline
\end{tabular}

TABEL 6.4 DIE BEVINDINGS VAN DIE AKADEMIESE VOORSPELLINGSWAARDE MET BEHULP VAN SWEEDSE FORMULE A MET SKOOLGROOTTOTAAL, WISKUNDE EN EERSTE TAAL AS VOORSPELLERS

\begin{tabular}{|c|c|c|c|c|c|c|c|c|c|c|c|c|c|}
\hline \multirow{3}{*}{\multicolumn{2}{|c|}{ SWEEDSE FORMULE }} & \multicolumn{6}{|c|}{1986} & \multicolumn{6}{|c|}{1987} \\
\hline & & \multicolumn{3}{|c|}{ SUKSES } & \multicolumn{3}{|c|}{ NIE SUKSES } & \multicolumn{3}{|c|}{ SUKSES } & \multicolumn{3}{|c|}{ NIE SUKSES } \\
\hline & & $\mathbf{f}$ & $k f$ & $\%$ & f & kf & 8 & $f$ & $\mathrm{kf}$ & $x$ & $f$ & $k f$ & $\%$ \\
\hline 0 & 4 & 0 & 9 & 100 & 0 & 8 & 100 & 0 & 23 & 100 & 0 & 16 & 100 \\
\hline 5 & 9 & 0 & 9 & 100 & 2 & 8 & 100 & 0 & 23 & 100 & 1 & 16 & 100 \\
\hline 10 & 14 & 1 & 9 & 100 & 1 & 6 & 75 & 1 & 23 & 100 & 3 & 15 & 94 \\
\hline 15 & 19 & 2 & 8 & 89 & 4 & 5 & 63 & 2 & 22 & 96 & 6 & 12 & 75 \\
\hline 20 & 24 & 1 & 6 & 67 & 1 & 1 & 13 & 5 & 20 & 87 & 1 & 6 & 38 \\
\hline 25 & 29 & 1 & 5 & 56 & 0 & 0 & 0 & 7 & 15 & 65 & 4 & 5 & 31 \\
\hline 30 & 34 & 0 & 4 & 44 & 0 & 0 & 0 & 2 & 8 & 35 & 1 & 1 & 16 \\
\hline 35 & 39 & 1 & 4 & 44 & 0 & 0 & 0 & 1 & 6 & 26 & 0 & 0 & 0 \\
\hline 40 & 44 & 1 & 3 & 33 & 0 & 0 & 0 & 3 & 5 & 22 & 0 & 0 & 0 \\
\hline 45 & 49 & 2 & 2 & 22 & 0 & 0 & 0 & 1 & 2 & 9 & 0 & 0 & 0 \\
\hline 50 & 54 & 0 & 0 & 0 & 0 & 0 & 0 & 1 & 1 & 4 & 0 & 0 & 0 \\
\hline 55 & 59 & 0 & 0 & 0 & 0 & 0 & 0 & 0 & 0 & 0 & 0 & 0 & 0 \\
\hline 60 & 64 & 0 & 0 & 0 & 0 & 0 & 0 & 0 & 0 & 0 & 0 & 0 & 0 \\
\hline 65 & 69 & 0 & 0 & 0 & 0 & 0 & 0 & 0 & 0 & 0 & 0 & 0 & 0 \\
\hline \multicolumn{2}{|c|}{ TOTAAL } & 9 & & & 8 & & & 23 & & & 16 & & \\
\hline
\end{tabular}


TABEL 6.5 DIE BEVINDINGS VAN DIE AKADEMIESE VOORSPELLINGSWAARDE MET BEHULP VAN DIE SWEEDSE FORMULE B MET SKOOLGROOTTOTAAL. EERSTE TAAL, WISKUNOE, NATUUR- EN SKEIKUNDE EN BIOLOGIE AS VOORSPEL-
LERS

\begin{tabular}{|c|c|c|c|c|c|c|c|c|c|c|c|c|}
\hline \multirow{3}{*}{$\begin{array}{l}\text { SWEEDSE FORMULE } \\
\text { (B) }\end{array}$} & \multicolumn{6}{|c|}{1986} & \multicolumn{6}{|c|}{1987} \\
\hline & \multicolumn{3}{|c|}{ SUKSES } & \multicolumn{3}{|c|}{ NIE SUKSES } & \multicolumn{3}{|c|}{ SUKSES } & \multicolumn{3}{|c|}{ NIE SUKSES } \\
\hline & $f$ & $k f$ & $\%$ & $f$ & $k f$ & $\%$ & $\mathbf{f}$ & $k f$ & $\%$ & $f$ & $k f$ & $\%$ \\
\hline $0-4$ & 0 & 9 & 100 & 0 & 8 & 100 & 0 & 23 & 100 & 0 & 16 & 100 \\
\hline $5-9$ & 0 & 9 & 100 & 0 & 8 & 100 & 0 & 23 & 100 & 0 & 16 & 100 \\
\hline $10-14$ & 0 & 9 & 100 & 1 & 8 & 100 & 1 & 23 & 100 & 2 & 16 & 100 \\
\hline $15-19$ & 1 & 9 & 100 & 5 & 7 & 88 & 1 & 22 & 96 & 7 & 14 & 88 \\
\hline $20-24$ & 3 & 8 & 89 & 2 & 2 & 25 & 5 & 21 & 95 & 4 & 7 & 44 \\
\hline $25-29$ & 1 & 5 & 56 & 0 & 0 & 0 & 7 & 16 & 70 & 2 & 3 & 19 \\
\hline $30-34$ & 2 & 4 & 44 & 0 & 0 & 0 & 5 & 9 & 39 & 0 & 0 & 0 \\
\hline $35-39$ & 1 & 2 & 22 & 0 & 0 & 0 & 3 & 4 & 17 & 0 & 0 & 0 \\
\hline $40-44$ & 1 & 1 & 11 & 0 & 0 & 0 & 1 & 1 & 4 & 0 & 0 & 0 \\
\hline & 9 & & & 8 & & & 23 & & & 16 & & \\
\hline
\end{tabular}

kandidate van 1986 en 1987 uitgesluit het. $25 \%$ van die studente van 1987 wat niesuksesvol is nie val in die interval 20-24.

\section{AANBEVELINGS VAN DIE NAVORSING}

Die akademiese voorspellingswaarde met behulp van die gewysigde Smeltzer, met skoolgroottotaal, wiskunde, natuur- en skeikunde, biologie en 'n derde taal blyk effektief te wees as die afsnypunt 60 is.

Dit wil voorkom of die akademiese voorspellingswaarde met behulp van die Sweedse formule A, met skoolgroottotaal, wiskunde, natuur-en skeikunde en biologie ' $n$ betekenisvolle voorspeller is van akademiese sukses as die afsnypunt 15 is. As daar egter by genoemde kombinasie voorspellers eerste taal gevoeg word blyk dit dat $25 \%(n=2)$ van die suksesvolle kandidate van die 1987 groep uitgeskakel sou wees. Daar is egter nog steeds $100 \%$ kandidate van die 1986 groep wat gekeur sou word. Aangesien die steekproef slegs twee jare insluit is 'n veralgemening moontlik onrealisties, alhoewel die afsnypunt 15 tog op hierdie stadium aanbeveel word.

Die afsnypunt 15 op die Sweedse formule A soos geilllustreer in Tabel 6.4 blyk aanbeveel te word as skoolgroottotaal, wiskunde en eerste taal as voorspellers gebruik word

Die akademiese voorspellingswaarde met behulp van die Sweedse Formule B met skoolgroottotaal, eerste taal, wiskunde, natuur-en skeikunde en biologie as voorspellers toon ook dat 15 as afsnypunt aan te beveel is.

\section{SLOT}

Die ondersoek is as voorlopige studie gedoen, aangesien slegs twee groepe ingesluit is. Dit blyk egter dat die effektiewe afsnypunte vir die gewysigde Smeltzer metode en die Sweedse formule 60 en 15 respektiewelik is. Die bevindings en resultate kan slegs verteenwoordigend beskou word in soverre hierdie groep studentverpleegkundiges as verteenwoordigend van die graadstudente in die Transvaal en moontlik die Republiek van Suid-Afrika beskou kan word.

\section{BIBLIOGRAFIE}

1. Basson, A.A. 1981. Die keuring van B.Cur studente aan die Randse Afrikaanse Universiteit, M.Cur-skripsie, Randse Afrikaanse Universiteit.

2. Fölscher, C.W., Van Huyssteen, M.C. 1978. Die keuring van studentverpleegkundiges aan die RAU - 'n oorsig. Curationis 1(3).
3. Furneaux, W.D. 1961. The chosen few. (An examination of some aspects on university selection in Britain). London: Nuffield Foundation, Oxford University Press.

4. Gouws, D.J. 1961. Die akademiese vordering en aanpassing van eerstejaar-studente - ' $n$ statistiese-kliniese studie, D.Phil-proefskrif, Universiteit van Pretoria.

5. Jacobs, G.J. 1987. A proposed method for the selection of university students. Bulletin for University Teachers. Vol. 19 No. 3. Rand Afrikaanse University.

6. Le Roux, W.H. 1976. Regte prognose steeds ontwykend. Unisa-nuus, No. 2.

7. Mearns, P.C. 1980. A review of the personal, social and academic characteristics of B.Sc. (Nursing) students at the University of the Witwatersrand for the period 1969-1978. Johannesburg M.Sc. verhandeling.

8. Smeltzer, C.H. 1965. Psychological evaluations in nursing education. New York: MacMillan

9. Stoker, D.J., Engelbrecht, C.S., Crowther, N.A.S., Du Toit, S. H.C., Herbst, A. 1985. Ondersoek na differensiële toelatingsvereiste tot tersiêre-onderwysinrigtings. Verslag WS 31, R.G.N.

Annali Basson (Mede-Professor, RAU) $D$. Verpleegkunde (US)

G.A.V., G.V.V., G.P.V., G.V., V.A., V.O. Annatjie Botes (snr Lektor, RAU) M. CUR (RAU), G.A.V., G.V.V., G.P.V., G.V., V.A., V.O. 